\title{
GRANDIOSE AND VULNERABLE NARCISSISM AND SUBJECTIVE WELLBEING - DOES GENDER MATTER?
}

\author{
Bogusława Lachowska \\ Institute of Psychology, John Paul II Catholic University of Lublin (Poland)
}

\begin{abstract}
The aim of the study was examination of the relationships between grandiose and vulnerable narcissism and subjective well-being (SWB) from a global perspective and in the area of close romantic relationships, as well as investigation whether gender moderates these relationships. The project was based on the person-environment fit theories, which suggest that personality is of great importance for the well-being of an individual in a given situation (Emmons, Diener and Larsen, 1986). A tripartite model of SWB was adopted, including positive affect and negative affect, and cognitive well-being (Diener, 1984). The subjects were 208 males and 207 females. Narcissistic Personality Inventory NPI, The Hypersensitive Narcissism Scale, The PANAS scale, Satisfaction With Life Scale, The Rosenberg Self-Esteem Scale, and ENRICH Marital Satisfaction Scale were applied. Hierarchical multiple regression analysis was performed. The effect of demographic variables and self-esteem were controlled. A positive correlation was observed between grandiose narcissism and overall satisfaction with life and positive affect, which was significantly stronger in the group of females than males. In the group of males, a negative relationship was found between grandiose narcissism and marital satisfaction and Idealistic Distortion. Vulnerable narcissism was positively correlated with negative affect in the group of males, and negatively correlated with marital satisfaction in the groups of males and females. While seeking an explanation for the differences in the importance of narcissism for wellbeing, it was assumed that males and females may differ with respect to the preferred self-esteem regulation strategies, resulting from differences in the socialization process.
\end{abstract}

Keywords: Grandiose narcissism, vulnerable narcissism, subjective well-being, marital satisfaction, gender.

\section{Introduction}

It is considered that personality is of great importance for the wellbeing of an individual (Diener and Lucas, 1999, McCrae and Costa, 1991). At present, narcissism, understood as personality trait, attracts the attention of many researchers. Grandiose and vulnerable narcissism are distinguished (Wink, 1991; Miller, Hoffman, Gaughan Gentile, Maples \& Campbell, 2011). These two forms of narcissism are manifested in various ways; however, they have the same background. The aim of the study is examination of the relationships between grandiose and vulnerable narcissism and subjective well-being (SWB) from a global perspective and in the area of close romantic relationships, as well as investigating whether gender moderates these relationships.

\section{Methods}

The subjects were 208 males and 207 females. Narcissistic Personality Inventory (NPI), The Hypersensitive Narcissism Scale, The PANAS scale, Satisfaction with Life Scale, The Rosenberg Self-Esteem Scale, and ENRICH Marital Satisfaction Scale were applied.

\section{Results}

A series of a three-stage hierarchical multiple regression analyses was conducted with wellbeing indices (Tab. 1- 5). The effect of demographic variables (type of relationship: marriage - 1/common law partnership - 2; having children: Yes - 1/No - 2), duration of relationship and self-esteem were controlled. 
Table 1. Summary of Hierarchical Analysis for Variables predicting satisfaction with life.

\begin{tabular}{|c|c|c|c|c|c|c|}
\hline Variable & \multicolumn{3}{|c|}{ Females } & \multicolumn{3}{|c|}{ Males } \\
\hline Step 1 & $\beta$ & $R^{2}$ & $\Delta R$ & $\beta$ & $R^{2}$ & $\Delta R$ \\
\hline Type of $r$. & -.14 & .01 & .01 & .05 & .005 & .005 \\
\hline Duration of $r$. & -.05 & & & .06 & & \\
\hline Children & .09 & & & -.05 & & \\
\hline Step 2 & & $.26 * * *$ & $25 * * *$ & & $.34 * * *$ & $.33 * * *$ \\
\hline Type of $r$. & $-.18 *$ & & & .06 & & \\
\hline Duration of $r$. & -.05 & & & .11 & & \\
\hline Children & .11 & & & -.01 & & \\
\hline Self-esteem & $.50 * * *$ & & & $.58 * * *$ & & \\
\hline Step 3 & & $.37 * * *$ & $11 * * *$ & & $.37 * * *$ & $.03 * *$ \\
\hline Type of $r$. & $-.19 *$ & & & .03 & & \\
\hline Duration of $r$. & -.03 & & & .12 & & \\
\hline Children & .08 & & & .02 & & \\
\hline Self-esteem & $.38 * * *$ & & & $.49 * * *$ & & \\
\hline vulnerable $n$. & -.004 & & & -.09 & & \\
\hline grandiose $n$ & $.36 * * *$ & & & $20 * *$ & & \\
\hline
\end{tabular}

Table 2. Summary of Hierarchical Analysis for Variables predicting negative affect.

\begin{tabular}{|c|c|c|c|c|c|c|}
\hline Variable & \multicolumn{3}{|c|}{ Females } & \multicolumn{3}{|c|}{ Males } \\
\hline Step 1 & $\beta$ & $R^{2}$ & $\Delta R$ & $\beta$ & $R^{2}$ & $\Delta R$ \\
\hline Type of $r$. & -.08 & .02 & .02 & 06 & .008 & .008 \\
\hline Duration of $r$. & $-.17 *$ & & & .001 & & \\
\hline Children & -.02 & & & 12 & & \\
\hline Step 2 & & $.26^{* * *}$ & $25 * * *$ & & $19 * * *$ & $18^{* * *}$ \\
\hline Type of $r$. & -.03 & & & -.07 & & \\
\hline Duration of $r$. & $-.16^{*}$ & & & -.04 & & \\
\hline Children & -.05 & & & .09 & & \\
\hline Self-esteem & $-.49 * * *$ & & & $-.43^{* * *}$ & & \\
\hline Step 3 & & $.28 * * *$ & .02 & & $24 * * *$ & $.05 * *$ \\
\hline Type of $r$. & -.03 & & & -.08 & & \\
\hline Duration of $r$. & -.14 & & & 01 & & \\
\hline Children & -.05 & & & .06 & & \\
\hline Self-esteem & $-.48 * * *$ & & & $-.46^{* * * *}$ & & \\
\hline vulnerable $n$. & .12 & & & $19 * *$ & & \\
\hline grandiose $n$. & .04 & & & .08 & & \\
\hline
\end{tabular}

Table 3. Summary of Hierarchical Analysis for Variables predicting positive affect.

\begin{tabular}{|c|c|c|c|c|c|c|}
\hline Variable & & Females & & & Males & \\
\hline Step 1 & $\beta$ & $R^{2}$ & $\Delta R$ & $\beta$ & $R^{2}$ & $\Delta R$ \\
\hline Type of $r$. & .07 & .004 & .004 & .001 & .02 & .02 \\
\hline Duration of $r$. & -.01 & & & -.16 & & \\
\hline Children & -.03 & & & -.11 & & \\
\hline Step 2 & & $.34 * * *$ & $.34 * * *$ & & $.27 * * *$ & $.25 * * *$ \\
\hline Type of $r$. & .01 & & & .02 & & \\
\hline Duration of $r$. & -.02 & & & -.11 & & \\
\hline Children & .01 & & & -.08 & & \\
\hline Self-esteem & $.58 * * *$ & & & $.50 * * *$ & & \\
\hline Step 3 & & $.49 * * *$ & $.15 * * *$ & & $.28 * * *$ & $.04 * *$ \\
\hline Type of $r$. & .01 & & & -.03 & & \\
\hline Duration of $r$. & .02 & & & -.09 & & \\
\hline Children & -.02 & & & -.06 & & \\
\hline Self-esteem & $.45 * * *$ & & & $.42 * * *$ & & \\
\hline vulnerable $n$. & .05 & & & -.08 & & \\
\hline grandiose $n$. & $.39 * * *$ & & & $23 * * *$ & & \\
\hline
\end{tabular}


Table 4. Summary of Hierarchical Analysis for Variables predicting marital satisfaction.

\begin{tabular}{|c|c|c|c|c|c|c|}
\hline Variable & \multicolumn{3}{|c|}{ Females } & \multicolumn{3}{|c|}{ Males } \\
\hline Step 1 & $\beta$ & $R^{2}$ & $\Delta R$ & $\beta$ & $R^{2}$ & $\Delta R$ \\
\hline Type of $r$. & 14 & .03 & .03 & -.02 & 001 & .001 \\
\hline Duration of $r$. & -.001 & & & .003 & & \\
\hline Children & .06 & & & .05 & & \\
\hline Step 2 & & $30 * * *$ & $27 * * *$ & & $14^{* * *}$ & $14^{* * *}$ \\
\hline Type of $r$. & 08 & & & -.01 & & \\
\hline Duration of $r$. & -.01 & & & .03 & & \\
\hline Children & .09 & & & 08 & & \\
\hline Self-esteem & $.52 * * *$ & & & $37 * * *$ & & \\
\hline Step 3 & & $31 * * *$ & $.02 *$ & & $24 * * *$ & $.10 * *$ \\
\hline Type of $r$. & .08 & & & 02 & & \\
\hline Duration of $r$. & -.03 & & & -.03 & & \\
\hline Children & .09 & & & .11 & & \\
\hline Self-esteem & $.51 * * *$ & & & $46^{* * *}$ & & \\
\hline vulnerable $n$. & $-.13 *$ & & & $-.20 * *$ & & \\
\hline grandiose $n$ & .06 & & & $-.23 * *$ & & \\
\hline
\end{tabular}

Table 5. Summary of Hierarchical Analysis for Variables predicting idealistic distortion.

\begin{tabular}{|c|c|c|c|c|c|c|}
\hline Variable & \multicolumn{3}{|c|}{ Females } & \multicolumn{3}{|c|}{ Males } \\
\hline Step 1 & $\beta$ & $R^{2}$ & $\Delta R$ & $\beta$ & $R^{2}$ & $\Delta R$ \\
\hline Type of $r$. & 12 & .009 & .009 & 02 & .001 & .001 \\
\hline Duration of $r$. & .05 & & & .003 & & \\
\hline Children & -.01 & & & -.01 & & \\
\hline Step 2 & & $.23 * * *$ & $.23 * * *$ & & $13 * * *$ & $13 * * *$ \\
\hline Type of $r$. & .08 & & & .03 & & \\
\hline Duration of $r$. & .04 & & & 03 & & \\
\hline Children & .02 & & & 02 & & \\
\hline Self-esteem & $48 * * *$ & & & $36^{* * *}$ & & \\
\hline Step 3 & & $.24 * * *$ & .01 & & $17 * * *$ & $04^{*}$ \\
\hline Type of $r$. & .07 & & & .06 & & \\
\hline Duration of $r$. & .03 & & & -.01 & & \\
\hline Children & .01 & & & .02 & & \\
\hline Self-esteem & $46^{* * *}$ & & & $.45 * * *$ & & \\
\hline vulnerable $n$. & -.09 & & & -.06 & & \\
\hline grandiose $n$. & -.002 & & & $-.21 * *$ & & \\
\hline
\end{tabular}

A positive correlation was observed between grandiose narcissism, and overall satisfaction with life and positive affect, which was significantly stronger in the group of females than males. In the group of males, a negative relationship was found between grandiose narcissism and marital satisfaction and Idealistic Distortion. Vulnerable narcissism was positively correlated with negative affect in the group of males, and negatively correlated with marital satisfaction in the groups of males and females.

\section{Discussion and conclusions}

While seeking an explanation for the differences in the importance of narcissism for wellbeing, it was assumed that males and females may differ with respect to the preferred self-esteem regulation strategies, resulting from differences in the socialization process.

\section{References}

Diener, E. \& Lucas, R. E., 1999, Personality and subjective well-being. In: D. Kahneman, E. Diener \& N. Schwartz (Eds.). Well-being: the foundations of hedonic psychology (213-229). New York: Russell Sage Foundation.

Diener, E., 1984, Subjective well-being. Psychological Bulletin, 95, 542-575.

Emmons, R. A., Diener, E. \& Larsen, R. J., 1986, Choice and avoidance of everyday situations and affect congruence: two models of reciprocal interactionism. Journal of Personality and Social Psychology, 51, 4, 815-826.

McCrae, R. R. \& Costa, P. T. Jr., 1991, Adding liebe und arbeit: The full five-factor model and well-being. Personality and Social Psychology Bulletin, 17, 227-232.

Miller, J. D., Hoffman, B. J., Gaughan, E. T., Gentile, B., Maples, J., \& Keith Campbell, W. (2011). Grandiose and vulnerable narcissism: A nomological network analysis. Journal of Personality, 79(5), 1013-1042.

Wink, P. (1991). Two faces of narcissism. Journal of Personality and Social Psychology, 61, 590-597. 